\title{
Three doses of oral misoprostol versus an intra-cervical Foley catheter for 24 hours for pre-induction cervical ripening in post-dated pregnancies: a randomized controlled trial
}

\author{
D Somirathne ${ }^{1}$, M Goonewardene ${ }^{2}$, L Dasanayake ${ }^{2}$ \\ (Index words: oral misoprostol, Foley catheter, cervical ripening)
}

\begin{abstract}
Objectives To compare three doses of oral misoprostol $50 \mu \mathrm{g}$ four hourly versus an intra-cervical Foley catheter for 24 hours, for pre-induction cervical ripening.

Methods Primary investigator blinded, randomized controlled trial conducted in 180 consecutive women with singleton uncomplicated pregnancies with Modified Bishop Score (MBS) $\leq 5$ at 40 weeks +6 days gestation, allocated by stratified (primigravida / multigravida) block randomization to receive three doses of oral misoprostol $50 \mu \mathrm{g}$ four hourly or an intra-cervical Foley catheter for 24 hours. MBS reassessed at 41 weeks gestation. If $M B S \geq 7$, induction of labour (IOL) with amniotomy and intravenous oxytocin infusion. If $M B S<7$, cross over therapy with intracervical Foley catheter for misoprostol group, vaginal prostaglandin $\mathrm{E}_{2}$ for Foley group.
\end{abstract}

Results At commencement, no significant differences in age, parity, body mass index and MBS between the two groups. Greater proportions established labour in both primigravidae (30\% vs. $9 \%$; RR $=4.4,95 \%$ Cl 1.3-14.6; $p=0.01$ ) and multigravidae (44\%.vs.16\%; RR=4.3; $95 \% \mathrm{Cl}$ $1.6-11.8 ; p=0.003)$ before 41 weeks of gestation in misoprostol group compared to the Foley group. Among the multigravidae, the mean increase of MBS was greater in the misoprostol group $(3.1 ; 95 \% \mathrm{Cl} 2.4-4)$ compared to the Foley group $(2.4 ; 95 \% \mathrm{Cl} 1.9-2.7, p=0.04)$. One primigravida and two multigravidae developed hyper stimulation after misoprostol therapy. No significant differences in the other maternal and perinatal outcomes.

Conclusions Compared to an intra-cervical Foley catheter for 24 hours, three doses of oral misoprostol 50 $\mu \mathrm{g}$ four hourly was more effective for cervical ripening and even resulted in IOL.

Ceylon Medical Journal 2017; 77-82

DOI: http://doi.org/10.4038/cmj.v62i2.8470

\section{Introduction}

Induction of labour (IOL) should be considered at 41 weeks gestation, especially in South Asia [1-3]. For IOL, artificial rupture of the membranes (amniotomy) and intravenous oxytocin infusion is being rapidly replaced worldwide by vaginal and oral prostaglandins, and oral misoprostol is likely to become the leading method for IOL in the future. Unfortunately, misoprostol was not registered for use in Sri Lanka until late 2015, due to concerns that its use could be abused by using it for abortions. Even currently the use of oral misoprostol for preinduction cervical ripening or IOL is not recommended as a routine practice. However, research on the use of oral misoprostol for pre induction cervical ripening has been carried out in Sri Lanka earlier, and further research on feasibility, generalizability, and the use of different doses and regimens of oral and vaginal misoprostol for pre-induction ripening of cervix and IOL for a live viable fetus at term, has been strongly recommended by the Director General of Health Services, Sri Lanka [4, 5].

The insertion of an intra-cervical Foley catheter is a frequently used procedure for pre induction cervical ripening and IOL [6-11]. Although this procedure may be associated with accidental rupture of membranes and infections, these risks do not appear to be significantly different from the risks of vaginal prostaglandins $[8,10]$. In most obstetric units in Sri Lanka the catheter is often removed after 24 hours, and an intravenous oxytocin infusion commenced, following amniotomy. However keeping the intra cervical Foley catheter up to three to four days has been shown to be safe and effective for IOL $[7,11]$. Vaginal prostaglandins are expensive and well known to cause uterine hyperstimulation which can lead to fetal compromise and even uterine rupture. These serious adverse effects are less with oral misoprostol $[2,10-16]$. The use of varying doses of oral misoprostol

${ }^{1}$ Teaching Hospital Mahamodara and ${ }^{2}$ Department of Obstetrics and Gynaecology, Faculty of Medicine, University of Ruhuna, Sri Lanka.

Correspondence: MG, e-mail: <malikg@eureka.lk>. Received 16 February 2017 and revised version accepted 25 April 2017.

This is an open-access article distributed under the terms of the Creative Commons Attribution License, which permits unrestricted use, distribution, and reproduction in any medium, provided the original author and source are credited. 
ranging from 20-200 $\mu$ g, at varying frequencies of 1-6 hours and the administration of up to 12 doses of $50 \mu \mathrm{g}$ over four days, have been reported [10-15]. However the optimum dose, frequency and duration of oral misoprostol are still being debated. It would be difficult to implement hourly, two hourly or three hourly regimens, especially in a busy obstetric unit. A previous randomized control trial (RCT) carried out at the University Unit of the Teaching Hospital Mahamodara Galle (THMG) showed that the administration of two doses of $25 \mu \mathrm{g}$ oral misoprostol four hours apart was feasible but the regimen was not as good as the insertion of an intra-cervical Foley catheter for 24 hours, for preinduction cervical ripening at term [4].

Insertion of an intra cervical catheter for 24 hours is a standard method frequently used for cervical ripening and IOL nationally as well as internationally. The commonest dose of oral misoprostol reported in the literature is $50 \mu \mathrm{g}$. It was decided to compare this standard method with three doses of oral misoprostol $50 \mu$ g administered four hourly, for cervical ripening in women with singleton uncomplicated pregnancies at 40 weeks +6 days of gestation having MBS $\leq 5$, which would indicate that the cervix was unfavourabe for IOL [17]. As ripening of the cervix and the establishment of labour are not mutually exclusive, separate entities but a continuum of processes, it was appreciated that onset of labour too could occur during the interventions, and if this occurred, the interventions would have exceeded expectations and have functioned as agents for IOL and not simply as agents for ripening of the cervix.

\section{Methods}

A single blinded randomized controlled trial (RCT) was carried out in the University Unit of the THMG from 1st September 2014 to 28th April 2015. In the previous RCT carried out in women at 40 weeks +6 days gestation, the proportions becoming favourable for IOL were $51.4 \%$ following two doses of oral misoprostol $25 \mu \mathrm{g}$ given four hours apart and $71.4 \%$ for insertion of intracervical Foley catheter for 24 hours. The objective of this study was to achieve $\geq 20 \%$ greater proportion becoming favourable for IOL with three doses of oral misoprostol 50 $\mathrm{\mu g}$ given four hourly, compared to insertion of an intra-cervical Foley catheter for 24 hours. The minimum sample size needed to detect this increase, (power of $80 \%$ and a confidence interval of 95\%) was 90 per study group, (total of 180 participants) [18].

Written informed consent was obtained from all women who fulfilled inclusion and exclusion criteria admitted to the University Obstetrics Unit at the THMG. Inclusion criteria were those not delivered by 40 weeks + 5 days gestation, having uncomplicated pregnancies with a singleton fetus, longitudinal lie and cephalic presentation. Exclusion criteria were pregnancy induced hypertension, gestational diabetes mellitus, multiple pregnancies, planned caesarean section, fetal growth restriction and scarred uteri. By 7.00 am the next morning, (at 40 weeks +6 days gestation), women were assessed for eligibility (MBS $\leq 5$ ) by the first author. Out of 220 women assessed, 180 participants were selected for randomization (Figure 1).

Using computer generated random numbers and stratified (primigravidae and multigravidae) blocks randomization, 184 sealed opaque envelopes containing the parallel allocation sequences for the two strata (92 primigravidae and 92 multigravidae) in blocks of four in a 1:1 ratio, were prepared by the second author, and kept securely in the antenatal ward.

An experienced medical officer inserted the intracervical Foley catheter with $60 \mathrm{ml}$ of normal saline in the bulb (Foley group) or supervised the oral administration by nursing staff of two tablets of misoprostol $25 \mu \mathrm{g}$ (Misogyn, Acme Formulation (P) Limited, Himachi Pradesh, India), at $7.30 \mathrm{am}, 11.30 \mathrm{am}, 3.30 \mathrm{pm}$ (misoprostol group), according to the predetermined allocation sequence. The first author was blind to this allocation. A 20 minute cardiotocograph (CTG) was carried out before commencement of the misoprostol and repeated if any participant developed labour pains occurring with a frequency of two or more per 10 minutes. As oral misoprostol should ideally be given on an empty stomach for improved bioavailability, the misoprostol was given 30 minutes before breakfast, lunch and evening tea. If labour was established, or pre labour rupture of membranes or any other complications occurred during the 24 hours after the intervention, they were managed according to the guidelines in the unit. The study was carried out during the week, from Monday to Friday. In the Foley group, if the Foley catheter had not fallen off, it was removed by the house officer at 6.30 am the next day. Throughout this period the first author was blind to the management of the patient. All the participants who had not been delivered by the next morning (41 weeks gestation), were examined at 7.00 am by the first author and their MBS was recorded. If the MBS was $\geq 7$, IOL was carried out with amniotomy and an intra-venous oxytocin infusion, as per the guidelines in the unit. If MBS was $<7$ after 24 hours of the intervention, the trial code was broken by the second author and cross over therapy was carried out (intra-cervical Foley catheter for misoprostol group and vaginal prostaglandin E2 for Foley group) by an experienced medical officer. The first author continued to be blind to this intervention too.

Age, parity, Body Mass Index (BMI) and the MBS were recorded at recruitment to the study. The number of participants establishing labour within 24 hours, the MBS and the change of MBS after 24 hours of the interventions, and the number of women becoming suitable for IOL with MBS $\geq 7$ after 24 hours of the interventions, were recorded. The induction delivery interval (IDI) following IOL, the mode of delivery, the reasons for operative delivery, maternal morbidity, hyperstimulation defined as 5 or more contractions per 10 minutes or duration of contraction $>120$ seconds, uterine rupture, peripartum hysterectomy, need for post-partum blood transfusion or crystalloid transfusion, need for intravenous antibiotics, 
maternal pyrexia of $\geq 38^{\circ}$ ) fetal and neonatal outcome and morbidity (suspicious or pathological CTG according NICE guidelines, meconium-stained liquor, birth weight, 1 minute Apgar scores, admission to the special care bay unit (SCBU) and the reasons for such admission), were also recorded [19]. An Apgar score $<3$ was considered as severe birth asphyxia [20]. The data were stored confidentially in a password protected, ongoing computer database by the first author. The randomized allocation sequence was kept confidentially by the second author, the first author was blinded to it, until data were entered in to the database.

Means and 95\% confidence intervals were calculated for the continuous variables and t-test was used for comparison of means. The medians and inter quartile ranges were calculated for the parity distributions and the Mann-Whitney U test was used to compare medians. The chi square test was used to compare proportions, the relative risks and their 95\% confidence intervals were calculated, and a $p$ value of $<0.05$ was considered to be statistically significant. The Statistical Package for Social Sciences (SPSS version 20) was used for data analysis.

Approval was obtained from the Ethical Review Committee, Faculty of Medicine, University of Ruhuna, and the trial was registered in the Sri Lanka Clinical Trials Registry (SLCTR No. 021 / 2014) [21].

\section{Results}

A total of 180 participants (Foley group=89, misoprostol group=91) were recruited for the study and they were all analysed (Figure 1). There were no significant differences in the distributions of age, parity, BMI and pre intervention MBS between the two groups (Table 1). Greater proportions established labour and delivered vaginally in both primigravidae [30\% vs. 9\%; $\mathrm{RR}=4.4$, (95\% CI 1.3-14.6); $p=0.01$ ) and multigravidae [44\% vs. 16; RR=4.3, (95\% CI 1.6-11.8); $p=0.003$ ] before 41 weeks of gestation after misoprostol therapy compared to the insertion of an intra-cervical Foley catheter. No significant differences were seen in the number of emergency caesarean sections (CS) prior to 41 weeks gestation between the two groups. Among the multigravidae, the mean increase of MBS was greater in the misoprostol group (3.1, 95\% CI 2.4-4) compared to the Foley group $(2.4,95 \%$ CI $1.9-2.7 ; p=0.04)$. There was no significant difference in the proportions becoming favourable for IOL between misoprostol and Foley groups in both primigravidae and multigravidae who did not establish labour and deliver vaginally prior to 41 weeks gestation (Table 2). The change in mean MBS however was significantly greater in primigravidae than in multigravidae in the Foley group [3.2, (95\% CI 2.6-3.8) vs. 2.3, (95\% CI 1.9-2.7); $p=0.04$ ).

There were no significant differences between the two groups in the mean IDI, the proportions delivering normally, requiring emergency CS or instrumental vaginal delivery in both primigraviade and multigravidae, following IOL at 41 weeks gestation (Table 3 ). In the primigravidae, two emergency CS were carried out in the misoprostol group due to fetal distress and hyperstimulation. In the Foley group two cases with suspected chorioamnionitis and one case with mild placental abruption had CS. In the multigravidae, two emergency CS were carried out in the misoprostol group due to uterine hyperstimulation, and one CS in the Foley group for suspected chorioamnionitis. All three cases of hyperstimulation occurred after the 3rd dose of oral misoprostol. Although inmultigravidae there were more cases of meconium stained liquor in the misoprostol group compared to the Foley group (6 vs. 2), the difference was not statistically significant. There were no significant differences in maternal or neonatal complications following either interventions in both multigravidae and primigravidae. One primigravida in misoprostol group and one multigravida in Foley group developed postpartum haemorrhage and they were managed medically. One intrapartum death, due to an undetected fetal hypoxia, occurred after IOL in a primigravida in the Foley group. No cases of uterine rupture were seen in the misoprostol group. There were no neonatal deaths in both intervention groups, there were no significant differences in outcomes between primigravidae and multigravidae (Tables 4-5). There were no significant differences in maternal, fetal or neonatal complications between both intervention groups in

Table 1. Basic characteristics of participants at 40 weeks +6 days gestation $(n=180)$

\begin{tabular}{|c|c|c|c|c|}
\hline & & Foley catheter $(n=89)$ & Misoprostol $(n=91)$ & $p$ \\
\hline \multirow{3}{*}{$\begin{array}{l}\text { Primigravidae } \\
\text { Age in years : }\end{array}$} & & $\mathrm{n}=44$ & $\mathrm{n}=46$ & \\
\hline & Range & 19-36 & $18-36$ & \\
\hline & Mean $(95 \%$ CI) & $26.3(25-27.6)$ & $26.3(24.9-27.7)$ & $0.96 *$ \\
\hline \multicolumn{2}{|c|}{ Mean Body Mass Index $(95 \% \mathrm{CI})$} & $20.3(20-21.6)$ & $21(20.2-21.8)$ & $0.67 *$ \\
\hline \multicolumn{2}{|c|}{ Mean pre intervention MBS (95\% CI) } & $3.6(3.2-4.0)$ & $3.6(3.2-4.0)$ & $0.95 *$ \\
\hline \multicolumn{2}{|l|}{ Multigravidae } & $\mathrm{n}=45$ & $\mathrm{n}=45$ & \\
\hline \multirow[t]{2}{*}{ Age in years : } & Range & $21-38$ & $20-42$ & \\
\hline & Mean $(95 \%$ CI) & $31.3(30.1-32.5)$ & 30.9 (29.331.5) & $0.67 *$ \\
\hline \multirow[t]{2}{*}{ Parity: } & Range & 1 to 4 & 1 to 4 & \\
\hline & Median (IQR) & $1(1-1)$ & $1(1-2)$ & $0.84 * *$ \\
\hline \multirow{2}{*}{\multicolumn{2}{|c|}{$\begin{array}{l}\text { Mean Body Mass Index }(95 \% \text { CI) } \\
\text { Mean pre intervention MBS }(95 \% \text { CI) }\end{array}$}} & $23.3(22.5-24.1)$ & $22.6(21.6-23.6)$ & $0.91 *$ \\
\hline & & $4.1(3.9-4.3)$ & $3.7(3.3-4.1)$ & $0.24 *$ \\
\hline
\end{tabular}

MBS = Modified Bishop's Score; IQR = Inter Quartile Range;

*by comparison of means with t-Test; **by comparison of medians with Mann-Whitney U test 
Table 2. Results at 41 weeks gestation $(n=180)$

\begin{tabular}{|c|c|c|c|c|c|c|c|c|}
\hline & \multicolumn{3}{|c|}{ Primigravidae $(n=90)$} & \multicolumn{5}{|c|}{ Multigravidae $(n=90)$} \\
\hline & $\begin{array}{c}\text { Misoprostol } \\
\quad(n=46)\end{array}$ & $\begin{array}{l}\text { Foley } \\
(n=44)\end{array}$ & $\begin{array}{c}R R \\
(95 \% C I)\end{array}$ & $p$ & $\begin{array}{c}\text { Misoprostol } \\
(n=45)\end{array}$ & $\begin{array}{l}\text { Foley } \\
(n=45)\end{array}$ & $R R(95 \% C I)$ & $p$ \\
\hline $\begin{array}{l}\text { Onset of labour and } \\
\text { VD within } 24 \text { hours } \\
\text { (\%) }\end{array}$ & $\begin{array}{c}14 \\
(30)\end{array}$ & $\begin{array}{c}4 \\
(9)\end{array}$ & $\begin{array}{c}4.4 \\
(1.3-14.6)\end{array}$ & $0.01 * *$ & $\begin{array}{c}20 \\
(44)\end{array}$ & $\begin{array}{c}7 \\
(16)\end{array}$ & $\begin{array}{c}4.3 \\
(1.6-11.8)\end{array}$ & $0.003 * *$ \\
\hline $\begin{array}{l}\text { Em CS within } 24 \\
\text { hours (\%) } \\
\text { MBS if not delivered } \\
\text { within } 24 \text { hours: }\end{array}$ & $\begin{array}{c}2 \\
(4)\end{array}$ & $\begin{array}{l}3 \\
(7)\end{array}$ & $\begin{array}{c}0.6 \\
(0.1-3.9)\end{array}$ & $0.61 * *$ & $\begin{array}{c}2 \\
(4)\end{array}$ & $\begin{array}{c}1 \\
(2)\end{array}$ & $\begin{array}{c}2 \\
(0.2-23)\end{array}$ & $0.56^{* *}$ \\
\hline $\begin{array}{l}\text { Range } \\
\text { Mean } \\
(95 \% \mathrm{CI})\end{array}$ & $\begin{array}{c}3-10 \\
6.3 \\
(5.5-7.1)\end{array}$ & $\begin{array}{c}2-9 \\
6.8(6.2-7.4)\end{array}$ & & $0.27 *$ & $\begin{array}{c}2-9 \\
6.8 \\
(6.2-7.4)\end{array}$ & $\begin{array}{c}3-9 \\
6.5 \\
(6.1-6.9)\end{array}$ & & $0.48^{*}$ \\
\hline $\begin{array}{l}\text { Change in MBS if not } \\
\text { delivered within } 24 \text { ho } \\
\text { Range } \\
\text { Mean } \\
(95 \% \mathrm{CI})\end{array}$ & $\begin{array}{c}0-8 \\
2.7 \\
(2.4-4)\end{array}$ & $\begin{array}{c}0-7 \\
3.2 \\
(2.7-3.7)\end{array}$ & & $0.89 *$ & $\begin{array}{c}0-8 \\
3.1 \\
(2.4-4)\end{array}$ & $\begin{array}{c}0-5 \\
2.4 \\
(95 \% \mathrm{CI})\end{array}$ & & $0.04 *$ \\
\hline $\begin{array}{l}\text { Favourable for IOL } \\
\text { (\%) }\end{array}$ & $\begin{array}{l}17 \\
(37)\end{array}$ & $\begin{array}{c}24 \\
(54)\end{array}$ & $\begin{array}{c}0.5 \\
(0.2-1.1)\end{array}$ & $0.09 * *$ & $\begin{array}{c}15 \\
(33)\end{array}$ & $\begin{array}{c}23 \\
(51)\end{array}$ & $\begin{array}{c}0.5 \\
(0.2-2.1)\end{array}$ & $0.49 * *$ \\
\hline $\begin{array}{l}\text { Needing cross over } \\
\text { therapy to further } \\
\text { ripen cervix (\%) }\end{array}$ & $\begin{array}{l}13 \\
(28)\end{array}$ & $\begin{array}{c}13 \\
(29)\end{array}$ & $\begin{array}{c}0.9 \\
(0.4-2.3)\end{array}$ & $0.89 * *$ & $\begin{array}{c}8 \\
(18)\end{array}$ & $\begin{array}{c}14 \\
(31)\end{array}$ & $\begin{array}{c}0.5 \\
(0.2-1.3)\end{array}$ & $0.39 * *$ \\
\hline
\end{tabular}

* by comparison of means with t-Test; **by comparison of proportions with Chi Square test; MBS = Modified Bishops Score;

Em CS = Emergency Caesarean Section; VD = Vaginal Delivery; IOL = Induction of Labour; RR = Relative Risk

Table 3. Comparison of induction of labour at 41 weeks gestation ( $n=79$ out of the 180)

\begin{tabular}{|c|c|c|c|c|}
\hline & & Misoprostol & Foley & $p$ \\
\hline Primigravidae & & $(n=17$ out of 46$)$ & $(n=24$ out of 44$)$ & \\
\hline \multicolumn{5}{|l|}{ Mean induction delivery } \\
\hline \multirow[t]{2}{*}{ interval (mins) } & Range & $80-640$ & $144-590$ & $0.5^{*}$ \\
\hline & Mean (95 \% CI) & $268(172-364)$ & 302 (238-366) & \\
\hline \multirow[t]{3}{*}{ Mode of Delivery } & Normal (\%) & $9(53)$ & $14(58)$ & $0.18^{* *}$ \\
\hline & Em.CS (\%) & $7(41)$ & $10(42)$ & $0.82 * *$ \\
\hline & Instrumental vaginal delivery & 1 & 0 & - \\
\hline Multigravidae & & $(n=15$ out of 45$)$ & $(n=23$ out of 45$)$ & \\
\hline \multirow[t]{2}{*}{ Mean induction delivery (mins) } & Range & $130-270$ & $105-480$ & $0.27 *$ \\
\hline & Mean $(95 \% \mathrm{CI})$ & 189 (159-219) & $226(180-272)$ & \\
\hline Mode of Delivery & Normal (\%) & $11(73)$ & $19(83)$ & $0.49 * *$ \\
\hline \multirow[t]{2}{*}{ Em. CS (\%) } & $4(27)$ & $4(17)$ & - & \\
\hline & Instrumental vaginal delivery & 0 & 0 & - \\
\hline
\end{tabular}

* by comparison of means with t-Test;

** by comparison of proportions with Chi square test; Em. CS = Emergency Caesarean Section

Table 4. Complications of the primary interventions $(n=180)$

\begin{tabular}{lcccc}
\hline & \multicolumn{2}{c}{ Primigravidae } & Multigravidae \\
\cline { 2 - 5 } & $\begin{array}{c}\text { Misoprostol } \\
(n=46)\end{array}$ & $\begin{array}{c}\text { Foley } \\
(n=44)\end{array}$ & $\begin{array}{c}\text { Misoprostol } \\
(n=45)\end{array}$ & $\begin{array}{c}\text { Foley } \\
(n=45)\end{array}$ \\
\hline Meconium stained liquor & 1 & 0 & $6(p=0.27)^{*}$ & 2 \\
Fetal tachycardia & 1 & 1 & 2 & 1 \\
Hyperstimulation & 1 & 0 & 2 & 0 \\
Postpartum Haemorrhage & 0 & 1 & 1 & 0 \\
Uterine rupture & 0 & 0 & 0 & 0 \\
APGAR<3 & 1 & 2 & 0 & 1 \\
Admission of neonate for intensive care & 2 & 1 & 1 & 1 \\
Perinatal death & 0 & 1 & 0 & 0 \\
\hline
\end{tabular}

* by comparison of proportions with Chi square test 
Table 5. Comparison of outcomes between primigravidae and multigavidae at 41 weeks gestation $(n=180)$

\begin{tabular}{|c|c|c|c|c|c|c|c|c|}
\hline \multirow{2}{*}{ Outcome } & \multicolumn{3}{|c|}{ Misoprostol $(n=91)$} & \multicolumn{5}{|c|}{ Foley $(n=89)$} \\
\hline & $\begin{array}{l}\text { Primi } \\
(n=46)\end{array}$ & $\begin{array}{c}\text { Multi } \\
(n=45)\end{array}$ & $\begin{array}{c}R R \\
(95 \% C I)\end{array}$ & $p$ & $\begin{array}{l}\text { Primi } \\
(n=44)\end{array}$ & $\begin{array}{c}\text { Multi } \\
(n=45)\end{array}$ & $\begin{array}{c}R R \\
(95 \% C I)\end{array}$ & $p$ \\
\hline \multicolumn{9}{|l|}{$\begin{array}{l}\text { Onset of labour and } \\
\text { vaginal delivery within } 24\end{array}$} \\
\hline hours of primary & & & 1.8 & & & & 1.8 & \\
\hline interventions & 14 & 20 & $(0.8-4.3)$ & $0.17 * *$ & 4 & 7 & $(0.5-6.8)$ & $0.35 * *$ \\
\hline Em. CS within 24 hours of & & & 1 & & & & 0.3 & \\
\hline primary interventions & 2 & 2 & $(0.1-7.6)$ & $0.98^{* *}$ & 3 & 1 & $(0.1-3.1)$ & $0.3^{* *}$ \\
\hline $\begin{array}{l}\text { Mean MBS in those not } \\
\text { delivered within } 24 \text { hours }\end{array}$ & & & & & & 6.5 & & \\
\hline $\begin{array}{l}\text { of primary interventions } \\
(95 \% \mathrm{CI})\end{array}$ & $\begin{array}{c}6.3 \\
(5.5-7.1)\end{array}$ & $\begin{array}{c}6.8 \\
(6.2-7.4)\end{array}$ & & $0.32 *$ & $\begin{array}{c}6.8 \\
(6.2-7.4)\end{array}$ & $(6.1-6.9)$ & & $0.48 *$ \\
\hline $\begin{array}{l}\text { Change in mean MBS in those } \\
\text { not delivered within } 24 \text { hours } \\
\text { of primary intervention, } \\
(95 \% \mathrm{CI})\end{array}$ & $\begin{array}{c}2.7 \\
(2.4-4)\end{array}$ & $\begin{array}{c}3.1 \\
(2.4-4)\end{array}$ & & $0.95 *$ & $\begin{array}{c}3.2 \\
(2.6-3.8)\end{array}$ & $\begin{array}{c}2.3 \\
(1.9-2.7)\end{array}$ & & $0.04 *$ \\
\hline Favourable for IOL at & & & 0.8 & & & & 0.9 & \\
\hline 41 weeks gestation & 17 & 15 & $(0.4-2)$ & $0.72 * *$ & 24 & 23 & $(0.4-2)$ & $0.74 * *$ \\
\hline
\end{tabular}

*by comparison of means with $t$ Test;

**by comparison of proportions with Chi Square Test; Primi = Primigravidae; Multi = Multigravidae; IOL = Induction of Labour; Em CS = Emergency Caesarean Section

primigravidae and multigravidae. In both primigravidae and multigravidae who needed cross over therapy there were no significant differences between the intervention groups in the mean IDI, the proportions delivering normally, requiring emergency CS or instrumental vaginal delivery.

\section{Discussion}

Compared to the Foley group, the proportion of women establishing labour and delivering vaginally within 24 hours in the misoprostol group was markedly greater in primigravidae as well as multigravidae. This indicates that three doses of 50 $\mathrm{gg}$ oral misoprostol administered four hourly has exceeded expectations and actually resulted in IOL. This confirms that oral misoprostol which acts as a systemic prostaglandin on the cervix as well as the myometrium can be used for pre-induction cervical ripening as well as for IOL. Furthermore, among those not establishing labour and delivering vaginally within the next 24 hours, multigravidae in the misoprostol group had a significantly greater increase in MBS compared to the Foley group after 24 hours. The slightly greater increase of the mean MBS in primigravidae compared to multigravidae in the Foley group is probably due to the slightly lower mean MBS in the primigravidae prior to the intervention. The absence of a statistically significant difference between the proportions becoming favourable for IOL after the two interventions, is therefore of no clinical value. Although there was one intra partum death due to unidentified fetal hypoxia in the Foley group, there were no significant differences in fetal or neonatal complications between the two groups, supporting the concept that oral misoprostol is also safe, although the current study was not powered to confirm this. The three cases of hyperstmulation in the misoprostol group emphasizes the need to adopted appropriate measures to identify hyperstimulation early and minimise its complications, just like with vaginal prostaglandins.
In the earlier study carried out in the unit, the two doses of oral misoprostol $25 \mu \mathrm{g}$ four hours apart was not as effective as an intra-cervical Foley catheter for 24 hours for pre-induction cervical ripening, most probably because of the low dose [4]. In a recently reported, large multi-center study from the Netherlands, (PROBATT II), wherein the oral misoprostol and the intra-cervical Foley catheter were continued up to four days, there was a greater proportion of women establishing labour after three doses of $50 \mu \mathrm{g}$ misoprostol administered orally four hours apart compared to the insertion of intra cervical Foley catheter for 24 hours (41.8\% vs 31.6\%; RR=1.33, 95\% CI 1.17-1.51; $p<0.001)$. This study has shown the safety of both these interventions over four days [11]. The interventions and outcomes of the current study are similar to the PROBATT II study where no significant differences were noticed in the CS rates, the IDI, and serious maternal or neonatal morbidity, between the groups. The only difference is that the primary outcomes of the current study were assessed after 24 hours while in the PROBATT II, the interventions were continued for four days. Both studies have shown that oral misoprostol is more effective for IOL than the insertion of an intra-cervical Foley catheter for 24 hours. The difference in the proportions establishing labour and delivering vaginally by 24 hours in the misoprostol group was significantly higher than the Foley group (25\% in current study vs $9.5 \%$ in PROBAT II). This is in spite of a larger volume of fluid ( $60 \mathrm{ml}$ ) being used for the bulb of the Foley in the current study compared to the $30 \mathrm{ml}$ used in the PROBAT II. The higher dose of 50 $\mathrm{g}$ oral misoprostol administered four hourly in the current study is apparently safe as shown by the PROBATT II study. The longer interval between doses of oral misoprostol, which is different to the WHO recommendations, as well as the titrated dose method, would be easier to be implemented especially in a busy obstetrics unit [2, 10,14]. 
The main strengths of the current study was that the first author, who assessed the participants before and after the interventions, was blinded until data entry had been completed and the fact that it contributes evidence to promote the use of oral misoprostol as an effective agent for IOL for a live viable fetus at term in Sri Lanka, although it was designed only to show superiority of oral misoprostol over the insertion of an intra-cervical Foley catheter for pre-induction cervical ripening. There were a few minor limitations in the study. It was stopped after recruiting 180 pregnant mothers on 28th April 2015 because the first author was transferred to another hospital on 1st May 2015. This resulted in a slight inequality of numbers of women in the two groups. Blinding of participants and the other caregivers was not feasible. The women would have had their early morning tea (but not the breakfast) prior to the first dose of oral misoprostol. The study was not conducted on Saturdays and Sundays. However these are unlikely to have affected the results significantly.

Oral misoprostol is relatively cheaper than the other methods of IOL, does not require refrigeration, has a long shelf life at room temperature, and is safe when there is a concern regarding a risk of ascending infection including vertical transmission of infections to the fetus. Therefore it can be used even in centers with limited economic resources. Further research is needed to establish the safest, effective and most convenient dosage regimen.

\section{Conclusions}

Compared to the insertion of an intra-cervical Foley catheter for 24 hours, three doses of oral misoprostol 50 micrograms given four hourly was more effective for pre-induction cervical ripening and even resulted in IOL.

\section{Conflicts of interest}

There are no conflicts of interest.

\section{References}

1. National Institute for clinical excellence. Inherited Clinical Guideline - Induction of Labour NICE clinical guideline 70, 2008. Available at http://guidance.nice.org.uk/CG70/ NICEGuidance/pdf/English (accessed on July 08, 2014).

2. World Health Organization. WHO Recommendations for induction of labour 2011. WQ440, World Health Organization, Geneva Switzerland.

3. Goonewardene M, Rameez MFM, Kaluarachchi A, Perera H. RHL Guideline Appraisal of the WHO recommendations for induction of labour (last revised: 01 November 2011). The WHO Reproductive Health Library; Geneva: World Health Organization.

4. Goonewardene M, Kumara DMA, Ziard MH, Bhabu B. Intra Cervical Foley Catheter vs Oral Misoprostol for Pre Induction Cervical Ripening of Postdated Pregnancies. Sri Lanka J Obstet and Gynaecol 2014; 36: 66-70.

5. Director General of Health services. Guidelines for Use of Misoprostol in Gynaecology and Obstetrics. Circular No: P-49/66/2015 [Ref:MSD/SCU(S)/Cir/2015] of 04.11.2015.
Ministry of Health and Indigenous Medicine, Colombo, Sri Lanka.

6. Cromi A, Ghezzi F, Tomera S, Uccella S, Lischetti B, Bolis PF. Cervical ripening with the foley catheter. Int J Gynaecol and Obstet 2007; 97: 105-9.

7. Ekele BA, Isah AY. Cervical ripening: how long can the Foley catheter safely remain in the cervical canal? African $J$ of Reprod Health 2002; 6: 98-102.

8. Jozwiak M, Bloemenkamp WMK, Kelly AJ, Mol WB, Irion O, Boulvain M. Mechanical methods for induction of labour. Cochrane Database of Syst Rev 2012, Issue 3. Art. No.: CD001233. DOI: 10.1002/14651858.CD001233.pub2.

9. Berndl A, El-Chaar D, Murphy K, Mc Donald Set. Does cervical ripening at term using a high volume foley catheter result in a lower caesarean section rate than a low volume foley catheter? A Systematic Review and Meta-Analysis. $J$ Obstet Gynecol Can 2014; 36: 678-87.

10. Chen W, Xue J, Peprah MK, et al. A systematic review and network meta-analysis comparing the use of Foley catheters, misoprostol, and dinoprostone for cervical ripening in the induction of labour. BJOG 2016; 123: 346-54.

11. ten Eikelder MLG, Rengerink KO, Joswiak M, etal. Induction of labour at term with oral misoprostol versus a Foley catheter( PROBAAT-Il ): a multicenter randomized controlled non-inferiority trial. The Lancet 2016; 387: 1619-28.

12. Alfirevic $Z$, Weeks A. Oral misoprostol for induction of labour, Cochrane Database of Syst Rev 2014.doi/10.1002/ 14651858.CD001338.pub2.

13. Jindal P, Avasthi K, Kaur M. A Comparison of Vaginal vs. Oral Misoprostol for Induction of Labor-Double Blind Randomized Trial. J Obstet and Gynecol India 2011; 61: 538-42.

14. Cheng S-Y, Ho Ming H, Lee J-C. Titrated Oral Compared With Vaginal Misoprostol for Labor Induction A Randomized Controlled Trial. Obstet Gynecol 2008; 111: 119-25.

15. Kehl S, Weiss C, Dammer U, et al. Induction of Labour: Change of Method and its Effects. Geburtsh Frauenheik 2015; 75: 238-43.

16. Maymon R, Shulman A, Pomeranz M, Holtzinger M, Haimovich L, Bahary C. Uterine rupture at term pregnancy with the use of intracervical prostaglandin E2 gel for induction of labor. Am J Obstet and Gynecol 1991; 165: 368-70.

17. Biswas A, Arulkumaran S. Induction of Labour in: Arulkumaran S, Rathnam S S, Bhasker Rao K Eds. The management of labour 1996; 14: 213-27 Orient Longman Ltd, Madras, India.

18. Kasiulevicius V, Šapoka R, Filipaviciute. Sample size calculation in epidemiological studies, Gerontologija 2006; 7: 225-31. Available at http://www.gerontologija.lt/files/ edit_files/File/pdf/2006/nr_4/2006_225_231. (accessed on July 08, 2014).

19. National Institute for clinical excellence. Interpretation of cardiotocograph traces in: Intrapartum care: NICE guideline CG190. Available from https://www.nice.org.uk/guidance/ cg190/resources/interpretation-of-cardiotocograph-tracestable-248732173 (accessed July 08, 2014).

20. International Statistical Classification of Diseases and Related Health Problems 10th Revision (ICD-10)-WHO Version for 2016, P21.0 http://apps.who.int/classifications/icd10/browse/ 2016/en\#!/P20-P29 (accessed on July 08, 2014].

21. Sri Lanka Clinical Trials Registry. Available at http:// trials.slctr.lk/trials/257. 